\title{
Ethical Matters in Rural Integrated Primary Care Settings
}

\author{
Daniel Mullin, PsyD, and Joseph Stenger, MD \\ University of Massachusetts Medical School
}

\begin{abstract}
Integrated primary care is particularly valuable to rural communities. Behavioral health care is often in short supply, and small or close-knit communities can intensify the stigma of seeking specialty mental health in rural settings. These and other barriers result in reduced access to needed behavioral health care. Nonetheless, rural practice of integrated primary care presents unique challenges to practitioners of multiple disciplines, including issues of competence, confidentiality, and dual relationships. This article provides an illustrative vignette to describe ethical issues in the rural practice of integrated primary care. It will review discipline-specific guidance in approaching these challenges and will offer recommendations for addressing disparities in the approaches of various disciplines engaged in the practice of integrated primary care.
\end{abstract}

Keywords: integrated primary care, collaborative care, rural, ethics

Integrated primary care brings together practitioners from a variety of backgrounds to provide tightly coordinated services that address the medical and behavioral needs of populations. This integration is particularly valuable to rural communities where behavioral health care is often in short supply, and the stigma of specialty mental health can further restrict access to needed care. The rural practice of integrated primary care presents unique challenges to practitioners of multiple disciplines who are bound by their own professional ethics codes. At times there is agreement between the respective ethics codes of different professions and at other times there can be disparities. Ethical practice in rural settings presents unique challenges, including issues of competence, confidentiality, and dual relationships. Different disciples, such as medicine, nursing, social work, psychology, and family therapy approach these challenges in their own way. This article will provide an illustrative vignette, which will describe ethical issues in the rural practice of integrated primary

Daniel Mullin, PsyD, and Joseph Stenger, MD, Department of Family Medicine and Community Health, University of Massachusetts Medical School.

Correspondence concerning this article should be addressed to Daniel Mullin, PsyD, University of Massachusetts Medical Center, Barre Family Health Center, 151 Worcester Road, Barre, MA 01005. E-mail: daniel.mullin@ umassmemorial.org care. It will review discipline-specific guidance (for psychologists and physicians) in approaching these challenges and will offer recommendations for addressing disparities in the approaches of various disciplines engaged in the practice of integrated primary care.

\section{Introduction to the Vignette}

Martha is a frail, 61-year-old single woman who works as a caregiver to her roommate, Olive. She was recently discharged from a family medicine service at a community hospital following a myocardial infarction. At the time of discharge the hospital team noted that the patient was in denial about her need to make changes to her lifestyle. They also noted that she had experienced a series of panic attacks prior to her discharge. The team was reassured when she informed them that her roommate, Olive, aged 79 would be able to assist in the days following her discharge.

Following her discharge from the hospital, her primary care physician (PCP), Dr. North, agreed to a home visit. Dr. North talked to the patient about her circumstances and the plan for follow-up care. Dr. North also suggested that Martha meet with the psychologist, Dr. Miller, who practices at the family health center. Dr. North also briefly spoke with Olive, Martha's roommate, about her hypertension medication as he was also her PCP. 
That evening at a local church event, Martha's pastor, Brandon, spoke to Dr. North about the recent home visit and his concerns about Martha and her social situation. He explained that Martha had moved in with Olive to be her caregiver in exchange for a place to live. Pastor Brandon expressed concern that the house was poorly kept and that there was occasionally not enough food for Olive or Martha. Because of Martha's recent hospitalization Olive was now the healthier of the two women and was caring for Martha, despite being too frail to do so safely. Pastor Brandon vocalized concern that Dr. North might not know Olive was potentially being exploited, though unintentionally, by Martha who was unable to live up to her responsibilities as a caregiver being paid by Olive.

Dr. North shared the details of Martha's circumstances with Dr. Miller, the health center's psychologist, who agreed to meet with Martha. Dr. North expressed concern about Martha's panic attacks and also expressed concern that her low weight had been a chronic problem. Five days after her discharge Martha attended an appointment with Dr. Miller at the health center. During this visit Martha vocalized her concerns about her diagnosis and feeling overwhelmed by episodes of anxiety when she tried to sleep. Martha also described her living arrangements with Olive.

After hearing more details of Martha's circumstances Dr. Miller realized that he had cared for Olive 6 months ago when she was struggling with symptoms of depression and stress. He also assessed Martha's relationship with food, and Martha acknowledged that she had been treated for an eating disorder when she was much younger. In his discussions with Dr. North following the initial session with Martha, Dr. Miller expressed confidence that he could assist her with her panic attacks. However, Dr. Miller expressed concern that Martha's eating disorder might be better treated by an expert, but she was unable to drive the 60 miles to the nearest clinic that specialized in eating disorders. Dr. Miller also expressed concern about his ability to care for Martha given his preexisting relationship with Olive.

\section{Ethical Issues Raised by the Vignette}

\section{Multiple Relationships}

The vignette above raises at least three relevant ethical issues. The most obvious of these issues is a concern about clinicians engaging in professional relationships with patients whose lives are intertwined and needs may be irreconcilable. Figure 1 provides a summary of the individuals involved, their roles, their relationship to the patient, and to each other. The figure provides an illustration of the multiple relationships described in the vignette. Although the issues of multiple relationships are not unique to rural practice, they are common there. Practice in a small community will increase the probability that individuals will come in contact with

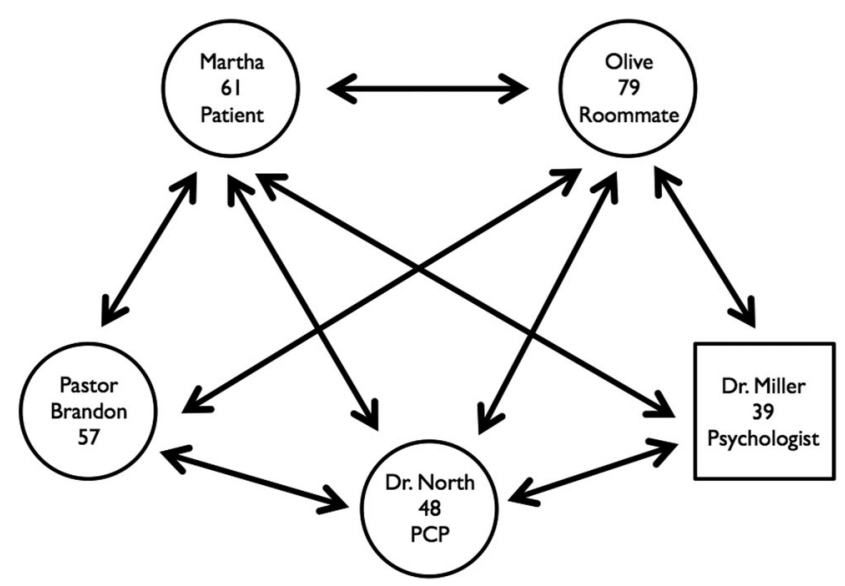

Figure 1. Vignette genogram. 
each other in a variety of settings and in a variety of personal and professional roles.

In the vignette above, a few of the multiple relationships of the health care professionals involved are worth investigating. Dr. North, the PCP, is engaged in numerous relationships, which include varied expectations. His pastor is also the pastor to Martha and Olive. He is the PCP for both Olive and Martha. Dr. North is also a colleague of Dr. Miller. In this vignette he is provided with information that indicates to him that one of his patients, Olive, has had a change to her living situation that may jeopardize her health. The important information he has acquired about his patient's health and living arrangements comes to him in a nonclinical encounter through his interactions with the pastor in the community.

Dr. Miller, the psychologist, is also presented with a common situation in rural practice. Without awareness or intention, he has entered into a working relationship with a patient, Martha, who has a close and complicated relationship with another patient, Olive, who is well known to him. Primary care behavioral health providers often have continuity relationships with their patients. It is possible that Olive still thinks of Dr. Miller as "her" psychologist. Dr. Miller is also a close collaborating partner with Dr. North who is also responsible for both patients' needs. It is not immediately clear how Dr. Miller can navigate his obligations to both Martha and Olive whose needs may be irreconcilable.

\section{Confidentiality}

Ethical dilemmas associated with confidentiality are common in rural health care practices. These issues are in part related to the issues of dual relationships discussed above. In smaller communities the ability to keep various relationships distinct can be challenging. The complexity of the relationships in Figure 1 is not an uncommon occurrence in rural practice. The multitudes of entangled relationships present challenges to both PCPs and psychologists.

In the vignette provided, Dr. North faces the common quandary of receiving relevant information about his patient's well-being outside of a clinical encounter. In small communities in particular, it is common that providers learn about their patients' relevant psychosocial issues while engaging in routine community activities. In the vignette above, Dr. North received information from a pastor while attending church.

Dr. Miller, the psychologist, was presented with an ethical dilemma when he learned that his new patient, Martha, was closely connected to another patient of his, Olive. As is often the case the relationship between his two patients was not clear until after Dr. Miller had entered a therapeutic relationship with Martha. Psychologists who are functioning as primary care behavioral health consultants (BHC) will frequently provide intermittent therapy to patients over the course of years. This practice is consistent with the primary care principle of continuity. In small, rural, communities, this continuity of care combined with the shortage of behavioral health providers and the interconnectedness of patients in the community, increases the probability that a BHC's patients will have close interpersonal connections in the community. It is not immediately clear to Dr. Miller whether he can disclose to Martha that he has a professional relationship with Olive. Likewise, it is not clear that Dr. Miller can ask Olive for consent to discuss the issue with Martha without first disclosing that he has met Martha professionally.

\section{Competence}

The vignette also raises the issue of scope of practice and competence, on behalf of Dr. Miller, the psychologist. BHCs practicing in primary care are called on to respond to a wide variety of symptoms and conditions in the undifferentiated patient. This is the nature of practice in primary care. In rural settings, where specialty care is often unavailable, the practicing BHC is often called on to care for patients whose needs might be better addressed in a specialty setting. In this vignette the diagnosis of an eating disorder is one of the presenting issues. This diagnosis gives Dr. Miller pause. $\mathrm{He}$ recognizes the clinical significance of the issue and is concerned that he may lack sufficient expertise to address the patient's needs.

Issues of competence and scope of practice on the part of physicians are not present in this vignette. Nevertheless, similar issues of competence apply to medical professionals practicing 
in rural primary care. For example, in medically urgent situations PCPs may be called on to provide care that stretches their confidence or competence. Physicians in rural practice are confronted with the potential harms their patients may experience if the physicians restrict their practice only to care for what they are fully qualified. In these situations, the provider may be called on to make an educated guess about what care holds the most promise and least risk.

\section{A Review of the Relevant Ethical Codes}

\section{The American Psychological Association}

The American Psychological Association's (APA, 2010) Ethical Principles of Psychologists and Code of Conduct provides clear guidance on the issues discussed above, including multiple relationships, confidentiality, and competence. The APA's Code offers specific guidance for the issues raised in the vignette as they relate to multiple relationships (Standard 3.05),

\section{If a psychologist finds that, due to unforeseen factors, a potentially harmful multiple relationship has arisen, the psychologist takes reasonable steps to resolve it with due regard for the best interests of the affected person and maximal compliance with the Ethics Code.}

The relevant principle to rural practice is to minimize harm. Where no other psychologist is available to care for a patient, it is essential to be clear to all parties about the boundaries of the relationships and to work to minimize harm.

The APA Code also provides specific guidance for maintaining confidentiality (Standard 4.01),

Psychologists have a primary obligation and take reasonable precautions to protect confidential information obtained through or stored in any medium, recognizing that the extent and limits of confidentiality may be regulated by law or established by institutional rules or professional or scientific relationship.

In addition, the general principles of Beneficence and Nonmaleficence as well as Respect for People's Rights and Dignity, which are outlined in the code, can be helpful for guiding psychologists who find themselves in a dilemma associated with confidentiality or multiple relationships.

It is in the area of competence that the APA Code provides the most clear guidance to psychologists practicing in rural settings [Standard $2.01(\mathrm{~d})]$,

\begin{abstract}
When psychologists are asked to provide services to individuals for whom appropriate mental health services are not available and for which psychologists have not obtained the competence necessary, psychologists with closely related prior training or experience may provide such services to ensure that services are not denied if they make a reasonable effort to obtain the competence required by using relevant research, training, consultation, or study.
\end{abstract}

For the purposes of the vignette above, this guidance suggests that Dr. Miller might consider providing treatment of Martha's eating disorder if he is able to secure reasonable consultation from someone more expert and if the patient is unable or unwilling to travel to see a clinician with more experience. In this vignette, Dr. Miller may choose to focus on providing treatment for the patient's panic disorder and limit his involvement with treating her eating disorder. He may decide to continue monitoring eating disorder symptoms while advocating for more specialized treatment should her eating disorder worsen.

Although rural practice can present unique challenges in adhering to the guidance provided, recommendations for approaching these situations include additional emphasis on strategies that are relevant to all psychologists. These strategies include being sure that each clinician has a thorough understanding of relevant ethics codes and state laws and regulations. In addition, it can be useful to clearly delineate the rules of confidentiality and its limits with patients. Likewise, expectations regarding boundaries related to contact outside of the office setting and phone calls seeking care without a visit can minimize risk. It can also be helpful to clearly document and acknowledge multiple relationships when they occur as well as plans to minimize risk associated with these relationships (Schank \& Skovholt, 1997).

\section{The American Medical Association}

The American Medical Association's (AMA, 2012) 2012-2013 Code of Medical Ethics does not expressly discuss the unique issues of rural practice. The AMA Code also does not discuss the conflicts that may arise from caring for two patients whose conflicting health needs may present physicians with a dilemma. The AMA Code does address issues of confidentiality and privacy (Principle IV), "A physician shall respect the rights of patients, colleagues, and 
other health professionals, and shall safeguard patient confidences and privacy with the constraints of the law." The code further delineates (Opinion 5.05),

The information disclosed to a physician by a patient should be held in confidence. The physician should not reveal confidential information without the express consent of the patient, subject to certain exceptions which are ethically justified because of overriding considerations.

Opinion 5.059 (Privacy in the Context of Health Care) states

Physicians must seek to protect patient privacy in all of its forms, including (1) physical, which focuses on individuals and their personal spaces, (2) informational, which involves specific personal data, (3) decisional, which focuses on personal choices, and (4) associational, which refers to family or other intimate relations. Such respect for patient privacy is a fundamental expression of patient autonomy and is a prerequisite to building the trust that is at the core of the patient-physician relationship.

However, the AMA Code does not provide guidance concerning the practical challenges of caring for a small community of patients where pragmatic issues of communication can challenge the requirement for maintaining privacy. Likewise, while the AMA Code expressly values competence (Principle 1), "A physician shall be dedicated to providing competent medical care, with compassion and respect for human dignity and rights," it does not acknowledge the stresses that rural practice places on the boundaries of competence.

The shortcomings of the AMA's Medical Code of Ethics with regards to rural practice are not surprising given its emphasis on providing extensive case law rather than on laying out in detail the general principles and strategies for resolving conflict between those principles or applying the principles in varied contexts. In general, the AMA Code provides more autonomy for physicians than the APA Code affords psychologists.

\section{Strategies for Resolving Interdisciplinary Discrepancies}

There are discrepancies between the guidance provided by the relevant Ethical Codes of Psychologists and Physicians as they pertain to the issues discussed in the vignette specifically and in rural practice in general.
Psychologists are provided with far more specific prohibitions from engaging in multiple relationships, violating confidentiality, or practicing beyond their competence. Furthermore, when these principles are challenged there is guidance for resolving those challenges. In contrast, physicians are not prohibited from engaging multiple relationships with patients and receive less clear guidance related to managing issues associated with confidentiality or competence.

It is reasonable to expect that psychologists and physicians practicing together may face challenges in resolving the discrepancies between their disciplines. It is first incumbent on to the professional with a more restrictive code to make their obligations known to those with whom they practice. In the case described above, it would be advisable for Dr. Miller to discuss his concerns regarding competence and multiple relationships with Dr. North.

Full informed consent in a care setting where access to specialists is limited, such as in rural health centers, can include reference to the patients choosing care in the home setting as opposed to choosing the more arduous choice of traveling to a distant facility, which provides more specialized services. This shared decision making can offset potential risks associated with a practitioner providing services that may exceed the usual interpretation of scope of service. If a provider feels uncertain about their own competence in a particular area, discussing this openly with colleagues at the site can provide essential feedback as guidance with appropriate scope of care. Further, this concern can be addressed by accessing online training or participating in listservs or other forms of asynchronous peer support and learning communities.

Finally, interested readers are referred to the thought provoking and engaging book titled, The Country Doctor Revisited: A Twenty-First Century Reader edited by Therese Zink (2010). It is a fantastic anthology of short stories, poems from clinicians of various backgrounds, and commentaries that reflect the realities and ethical quandaries of practice in rural settings. The book offers few concrete solutions, but it is rich in its approach to revealing both the substantial rewards and inherent challenges of rural health care. 


\section{References}

American Medical Association. (2012). Code of Medical Ethics 2012-2013: Current Opinions With Annotations. Chicago, IL: Author.

American Psychological Association. (2010). 2010 Amendments to the 2002 "Ethical principles of psychologists and code of conduct." American Psychologist, 65, 493. doi:10.1037/a0020168

Schank, J. A., \& Skovholt, T. M. (1997). Dualrelationship dilemmas of rural and small-commu- nity psychologists. Professional Psychology: Research and Practice, 28, 44.

Zink, T. (2010). The country doctor revisited: A twenty-first century reader. Kent, $\mathrm{OH}$ : Kent State University Press.
Received January 8, 2013

Accepted January 16, 2013 